\title{
Intrapartum PCR assay is a fast and efficient screening method for Group B Streptococcus detection in pregnancy
}

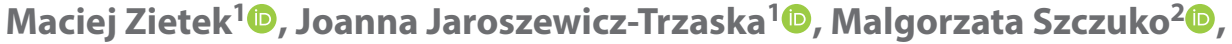 \\ Radoslaw Mantiuk ${ }^{3}$, Z Zbigniew Celewicz ${ }^{1}$ (1) \\ ${ }^{1}$ Department of Perinatology, Obstetrics and Gynecology, Pomeranian Medical University, Szczecin, Poland \\ ${ }^{2}$ Department of Human Nutrition and Metabolomics, Pomeranian Medical University, Szczecin, Poland \\ ${ }^{3}$ Department of Computer Science, University of Szczecin, Szczecin, Poland
}

\begin{abstract}
Objectives: The aim of the study is to verify the usefulness of a real-time polymerase chain reaction versus the culture for ante- and intrapartum group B Streptococcus maternal colonization (GBS) and prevalence of discordance during the period between an antepartum screening and delivery.

Material and methods: The study involved 106 pregnant women aged 18 to 39 years. Rectovaginal samples were collected according to CDC guidelines at 35-37 weeks of gestation as well as in the first stage of labour, during physical examination and were analyzed using two independent diagnostic methods: microbiological culture with standard culture and polymerase chain reaction with real-time assay.

Results: The discordance between antenatal and intrapartum GBS prevalence has been demonstrated as well as differences associated with diagnostic strategies, culture and PCR.

Conclusions: Intrapartum detection of GBS colonization using culture or Real-Time PCR assay as well, regardless of antenatal screening test for GBS, is very useful in identifying women who require implementation or withdrawal from prophylactic intrapartum antibiotic therapy. Real-Time PCR is a quick efficient method for GBS screening in pregnant women, which can be even applied during labor due to its short time of analyzing and high sensitivity and specificity. The above fact may indicate the need to perform the GBS test in the intrapartum period in all pregnant GBS negative women using PCR assay as a more adequate diagnostic method as the procedure could reduce the risk of a neonatal GBS infection subsequently to a prophylactic antibiotic therapy in women with an intrapartum positive GBS.
\end{abstract}

Key words: group B Streptococcus; vaginal colonization; real-time polymerase chain reaction; pregnancy

Ginekologia Polska 2020; 91, 9: 549-553

\section{INTRODUCTION}

Group B Streptococcus (GBS) are $\beta$-hemolytic, Gram-positive bacteria that are a leading cause of neonatal infections and maternal GBS colonization during pregnancy is associated with a higher incidence of ascending infection or GBS transfer to the newborn during labor [1]. An independent risk factor for GBS colonization in pregnant women is gestational diabetes [2]. The GBS direct contact with amniotic cavity or placenta may lead to inflammation of the membranes which is associated with premature birth or stillbirth [3-6]. In addition, group B Streptococcus is the leading cause of sepsis and meningitis in the first 3 months of life $[7,8]$ and in 1 to $3 \%$ of children it may cause a severe early-onset group B Streptococcus infection within seven days after birth, with a neonatal mortality rate of around $12 \%$ [9]. It is estimated that the incidence of women with vaginal/rectal GBS colonization is $30 \%$ and the infection is mostly asymptomatic [10]. The GBS culture identification using microbiological methods with swabbing from the vaginal and rectal area remains the gold standard $[11,12]$. The results are obtained after 48-72 hours and have low predictive value of the positive result [13]. As a GBS colonization in pregnancy remains the most important risk factor for newborn disease due its vertical transmission during delivery, the time of GBS detection with immediate antibiotic prophylaxis implementation plays a crucial role. Many assays focus therefore on GBS screening in attempt to validate the fastest and the most effective method. Real-Time PCR screening during labor has 
Table 1. Maternal and neonatal demographic characteristics

\begin{tabular}{|l|l|}
\hline Age (years) & $29.1 \pm 4.9$ \\
\hline Nullipara $\mathrm{n}(\%)$ & $66(62.3)$ \\
\hline Maternal weight at delivery $(\mathrm{kg})$ & $79.5 \pm 12.9$ \\
\hline Height $(\mathrm{cm})$ & $166.2 \pm 5.8$ \\
\hline $\mathrm{BMI}\left(\mathrm{kg} / \mathrm{m}^{2}\right)$ & $28.7 \pm 4.1$ \\
\hline Mean duration of gestation (weeks) & $39 \pm 1.2$ \\
\hline Rupture of membranes $>18$ hours $\mathrm{n}(\%)$ & $4(3.8)$ \\
\hline GDM $\mathrm{n}(\%)$ & $22(20.7)$ \\
\hline Cesarean section $\mathrm{n}(\%)$ & $26(24.5)$ \\
\hline Newborns birth weight $(\mathrm{g})$ & $3368.7 \pm 421.3$ \\
\hline Early-onset infection $\mathrm{n}(\%)$ & $2(1.9)$ \\
\hline Late-onset infection $\mathrm{n}(\%)$ & $0(0)$ \\
\hline
\end{tabular}

Data are means \pm SD

the advantage of providing results within 1-2 hours with high specificity and sensitivity.

Recently the Cepheid Xpert GBS kit in the GeneXpert ${ }^{\oplus}$ Dx system is found to have been used as a GBS screening method. An automated PCR-assay with vaginal/rectal swab testing for GBS during labor may reduce the incidence of unnecessarily given intrapartum antibiotic prophylaxis (IAP) as well as can be useful for the selection of women to whom IAP should be offered, due to its high sensitivity of $85.71-89 \%$ and specificity of 90-95.9\% [14-16].

\section{Objectives}

The aim of the study is to verify the usefulness of a real-time polymerase chain reaction versus the culture for ante- and intrapartum group B Streptococcus maternal colonization (GBS) and prevalence of discordance during the period between an antepartum screening and a delivery.

\section{MATERIAL AND METHODS}

The study involved 106 women aged from 18 to 39 years (mean $29.1 \pm 4.9$ ) giving birth at the Department of Perinatology, Obstetrics and Gynecology in Szczecin, Poland in the period 01.10-30.10.2018 and their children (Tab. 1). The inclusion criterion was current term pregnancy (from 37 weeks to 42 weeks), preliminary qualification for vaginal route delivery and the presentation of microbial culture for GBS, taken from vagina/rectal area as a part of routine screening test performed between 35 and 37 weeks of gestation. This investigation did an analysis to establish the prevalence and discordance of GBS colonization among Caucasian women.

Rectovaginal samples were collected from all pregnant women being in the intrapartum period according to CDC guidelines, during a physical examination and were analyzed using two independent diagnostic methods: micro- biological culture with standard culture and Real-Time PCR analysis. The material was taken from the vaginal vestibule (without using vaginal speculum) and anus (above the external sphincter) using sterile swabs, appropriate for the given method of determination. After delivery, newborns swabs were taken from the ear and anus and standard culture was performed for bacterial strains identification.

A specimen collection and microbiological culture.

Swabs were collected on a transport medium, not containing activated carbon. In the laboratory, the swabs were used to inoculate two culture tubes and transferred into the tamped medium with addition of gentamicin Todd-Hewitt $(8 \mu \mathrm{g} / \mathrm{mL})$ and nalidixic acid $(15 \mu \mathrm{g} / \mathrm{mL})$. Secondary cultures were incubated for $24-48 \mathrm{~h}$ at $35-37^{\circ} \mathrm{C}$ on air or in a $5 \%$ enriched atmosphere $\left(5 \% \mathrm{CO}_{2}\right)$. After an incubation operation, a small number of cultures were streaked on an improved solid medium ( $5 \%$ sheep blood agar plates). The plates were re-incubated for $18-24$ hours at $35-37^{\circ} \mathrm{C}$ on air or in a $5 \%$ enriched atmosphere $\left(5 \% \mathrm{CO}_{2}\right)$. After gaining the GBS-corresponding colony grow (characteristic narrow zone of beta-hemolysis), the Gram-positive, catalase-negative grains were identified. In doubtful cases, the CAMP (Christi, N. E. Atkins i E. Munch-Peterson) test were used for presumptive identification of Group B beta-hemolytic streptococci, Streptococcus agalactiae.

For the rapid identification of GBS colonization, in vitro diagnostic tests were used to detect GBS DNA from enriched vaginal and rectal specimens. The Xpert GBS tests of the Cepheid Xpert GBS system were used for this purpose based on a fully automated Real-Time PCR polymerase chain reaction with fluorogenic detection of the amplified DNA. After collecting the swab, it was placed in Lim broth for the enrichment and a secondary clean swab (Cepheid) dipped into the enrichment broth specimen was put in the designated chamber of the cartridge. Once the DNA solution is obtained, mixing with dry PCR reagents is performed. After the transfer into the integrated reaction tube for real-time PCR, the GBS detection takes place. On the base of fluorescent signals measurement and embedded calculation algorithms, the GeneXpert Instrument Systems interpolates the results. A fully automated GBS detection procedure using GeneXpert Instrument Systems takes about 75 minutes and the results are presented in the tables and graphically.

The sensitivity, specificity, positive predictive value and negative predictive value of the Real-Time PCR assay were separately counted with the antepartum or intrapartum culture as the reference. A Fisher's exact test was used for statistical significance $(p>0.05)$ and to analyze the differences among group means in a sample, the analysis of variance (ANOVA) has been used. Statistical analyses were performed with the use of MacStats version 1.01. 


\begin{tabular}{|c|c|c|c|c|}
\hline \multirow{2}{*}{ n (\%) } & \multicolumn{4}{|c|}{$\begin{array}{l}\text { Antepartum screening } \\
106(100)\end{array}$} \\
\hline & \multicolumn{2}{|c|}{$\begin{array}{l}\text { A-CS (+) } \\
29(27.3)\end{array}$} & \multicolumn{2}{|l|}{$\begin{array}{l}\text { A-CS (-) } \\
77(72.7)\end{array}$} \\
\hline \multirow{4}{*}{$\begin{array}{l}\text { Intrapartum } \\
\text { screening } \\
106(100)\end{array}$} & $\begin{array}{l}\text { I-CS (+) } \\
12(41.4)\end{array}$ & $\begin{array}{l}\text { I-CS (-) } \\
17(58.6)\end{array}$ & $\begin{array}{l}\text { I-CS (+) } \\
8(10.4)\end{array}$ & $\begin{array}{l}\text { I-CS (-) } \\
69(89.6)\end{array}$ \\
\hline & $\begin{array}{l}\text { I-PCR (+) } \\
20(69)\end{array}$ & $\begin{array}{l}\text { I-PCR (-) } \\
9(31)\end{array}$ & $\begin{array}{l}\text { I-PCR (+) } \\
9(11.7)\end{array}$ & $\begin{array}{l}\text { I-PCR (-) } \\
68(88.3)\end{array}$ \\
\hline & $\begin{array}{l}\text { I-CS (+) } \\
\text { I-PCR (+) } \\
10(34.5)\end{array}$ & $\begin{array}{l}\text { I-CS (-) } \\
\text { I-PCR (-) } \\
7(24.1)\end{array}$ & $\begin{array}{l}\text { I-CS (+) } \\
\text { I-PCR (+) } \\
{ }^{*} 8(10.4)\end{array}$ & $\begin{array}{l}\text { I-CS (-) } \\
\text { I-PCR (-) } \\
{ }^{*} 68(88.3)\end{array}$ \\
\hline & $\begin{array}{l}\text { I-CS (-) } \\
\text { I-PCR (+) } \\
10(34.5)\end{array}$ & $\begin{array}{l}\text { I-CS (+) } \\
\text { I-PCR (-) } \\
2(6.9)\end{array}$ & $\begin{array}{l}\text { I-CS (-) } \\
\text { I-PCR (+) } \\
1(1.3)\end{array}$ & $\begin{array}{l}\text { I-CS (+) } \\
\text { I-PCR (-) } \\
0\end{array}$ \\
\hline $\begin{array}{l}\text { GBS infection of } \\
\text { newborn }\end{array}$ & \multicolumn{2}{|l|}{ None } & ${ }^{*} 1(1.3)$ & ${ }^{*} 1(1.3)$ \\
\hline
\end{tabular}

A-CS - Antepartum culture screening; I-CS - Intrapartum culture screening; I-PCR - Intrapartum PCR assay

\section{RESULTS}

Of the 106 pregnant women included in the analysis, in 29 (27.3\%) cases microbiological cultures for GBS collected from the vagina/rectum in the antepartum period were positive, while a negative result was found in 77 (72.7\%) pregnant women. In the group of antenatal GBS positive women ( $n=29$ ), a positive result of intrapartum microbiological culture from vagina/rectum was obtained in 12 (41.4\%) women, while the positive result has been confirmed by PCR in 20 (69\%) women. In the group of antenatal GBS positive women, a negative result in intrapartum culture was obtained in 17 (58.6\%) women, while the PCR showed a negative result only in 9 (31\%) women (Fig. 1). The positive result in an ante- and intrapartum test confirmed by two methods (culture, PCR) was demonstrated in 10 (34.5\%) of 29 women. On the other hand, the conversion from GBS positive test to negative GBS test in the intrapartum period confirmed by two methods (culture, PCR) was demonstrated in 7 (24.1\%) of 29 women. In 10 (34.5\%) cases of 29 GBS positive women in the antepartum period, the intrapartum GBS test was negative in culture and positive in PCR, while in 2 (6.9\%) cases the intrapartum GBS test was positive in culture and negative in PCR (Tab. 1). In all women with a positive result of antepartum GBS, no GBS infection was found in newborns regardless of maternal intrapartum GBS status. In the group of GBS negative women in antepartum screening $(n=77)$, a positive result of intrapartum culture was obtained in 8 (10.4\%) women, while the PCR test was positive in $9(11.7 \%)$ women. In one case, where the conversion of antepartum negative to positive result confirmed in both the culture and PCR was demonstrated, the newborn was born with GBS infection but did not develop
Table 3. Sensitivity, specificity, and predictive values for the PCR assay and culture screening for the detection of GBS in the cohort of 106 pregnant women [\%]

\begin{tabular}{|l|l|l|}
\hline Performance & $\begin{array}{l}\text { Antpartum } \\
\text { culture }\end{array}$ & $\begin{array}{l}\text { Intrapartum } \\
\text { PCR assay }\end{array}$ \\
\hline Sensitivity & 64.7 & 81.8 \\
\hline Specificity & 90.3 & 86.9 \\
\hline Positive predictive value (PPV) & 75.9 & 62.1 \\
\hline Negative predictive value (NPV) & 84.4 & 94.8 \\
\hline
\end{tabular}

sepsis in the further course of the disease. In the group of women with negative GBS test in the antepartum period, the negative result in intrapartum culture was obtained in $69(89.6 \%)$ women whereas the PCR showed a negative result in 68 (88.3\%) women (Fig. 1). Paradoxically, in one case, in which ante- and intrapartum tests (culture and PCR) were negative for GBS, the newborn was born with a GBS infection but did not develop sepsis in the further course of the disease. Also, in one case with maternal negative ante- and intrapartum GBS culture and negative intrapartum PCR but positive intrapartum culture, a GBS infection was found in the newborn which did not result in sepsis. The assessment of the diagnostic reliability of used methods is presented in Table 2. The study shows that the diagnosis of GBS colonization using PCR method indicates a high sensitivity in those women in whom GBS was found to be present in intrapartum culture screening. The lack of colonization of GBS detected by PCR assay equally applies to women in whom the presence of GBS in the culture has not been demonstrated before delivery as well as in an intrapartum test, showing a high specificity in this respect. The analysis of variance did not show any relationship between GBS positive tests (antenatal and intrapartum culture and PCR assay) and the occurrence of gestational diabetes mellitus. The correlation between GBS colonization and the time of premature rupture of membranes has not been proved as well. Regardless of the time that passed from premature rupture of membranes (PROM) and the way of delivery (a vaginal vs cesarean section), the tendency to colonize with GBS was similar.

\section{DISCUSSION}

Based on a cohort study conducted in the period 2003-2015 in 60029 pregnant women, colonization with GBS streptococcus was found in $21.6 \%$ of women, GBS negative was demonstrated in $78.3 \%$ and invasive symptomatic GBS infection was detected in $0.1 \%$ of pregnant women [17]. In our material, the percentage of colonized pregnant women was similar and amounted to $27.3 \%$, while the negative result was found in $72.7 \%$ of cases. There was no case of symptomatic GBS infection in women. Regardless of the presence of 
GBS colonization in the rectovaginal area (chronic, transient or intermittent) in both pregnant and non-pregnant women, its incidence is within 15-35\% [18]. Young BC et al. demonstrated differences in the occurrence of GBS colonization, depending on the time when samples were collected for culture. When a swab was taken in the antenatal period, GBS positive results were found in $19.5 \%$ of women, compared with $23.8 \%$ of women who had performed the intrapartum GBS screening test. It has been demonstrated that there is a discordance of GBS cultures collected in the antenatal period and those collected in the intrapartum period, amounting to as much as $10.4 \%$ [18-20]. We obtained similar results in our investigation where among 77 women GBS negative in the antenatal period, the positive culture test was found in 8 (10.39\%) and positive PCR assay in 9 (11.69\%) individuals. It is reported that the antenatal microbiological screening test has the sensitivity of about $60 \%$ and a relatively low specificity [16, 19-21]. Our studies confirmed a high sensitivity of intrapartum PCR assay when compared to antenatal culture, which is consistent with other studies [22-25]. This result is important because as it has been shown in Young et al. report, majority of newborns with sepsis was born from women with GBS negative antenatal screening test and subsequently without the IAP [18]. In our material, among 3 newborns born with GBS infection, 2 newborns came from GBS negative mothers in the antenatal period who did not receive IAP. The above fact may indicate the need to perform the GBS test in the intrapartum period in all pregnant GBS negative but also positive women. The above procedure could reduce the risk of neonatal infection in women with conversion to positive GBS in which IAP has been implemented. In turn, in the group of women with antenatal false-positive GBS result, GBS intrapartum assay would be conclusive, especially when performed using PCR assay and could reduce the incidence of unnecessary IAP. When taking the time of procedure for consideration, the use of Cepheid Xpert GBS is a more adequate method for rapid GBS colonization detection as well as facilitating qualification for antibiotic prophylaxis during labor [1]. In the Plaivert et al. [22] studies, out of 565 women with antenatal positive GBS, only 335 (59.3\%) confirmed GBS presence in the intrapartum test regardless of a diagnostic method which proves the unnecessary use of prophylactic antibiotics in almost $40 \%$ of women. Our results turned out to be even more unsatisfactory. Among antenatally colonized women only $41.4 \%$ confirmed the GBS presence in intrapartum PCR assay. According to the literature, a GBS identification using PCR is a sensitive and specific method acceptable for an intrapartum GBS screening $[22,23]$. The meta-analysis of intrapartum GBS colonization conducted among 6368 pregnant women in 15 studies showed high sensitivity (93.7\%) and specificity (97.6\%) of the PCR assay in relation to the microbiological methods which due to rapid result determines the $P C R$ superiority [26]. Also, in our investigation, despite the relatively small analyzed group, the PCR method proved to be a useful diagnostic tool during delivery. According to Helmig et al. an intrapartum PCR assay is an adequate diagnostic tool to qualify patients for prophylactic antibiotic therapy [23]. In our study, the relationship between two variables: time elapsed from PROM to delivery and incidence of GBS colonization has not been confirmed regardless of the diagnostic method used (PCR, culture), which is consistent with studies of other investigators [27]. In a study conducted by Victoria Parente et al. [28], an early fetal rupture of membranes over 18 hours was associated with a slightly higher chance of occurrence of GBS colonization (OR 1.38).

\section{CONCLUSIONS}

We conclude that intrapartum detection of GBS colonization using culture or Real-Time PCR assay as well, regardless of antenatal screening test for GBS, is very useful in identifying women who require implementation or withdrawal from prophylactic intrapartum antibiotic therapy. Real-Time PCR is a quick efficient method for GBS screening in pregnant women, which can be even applied during labor due to its short time of analyzing and high sensitivity and specificity.

\section{Conflict of interest}

The authors declare that there is no conflict of interest regarding the publication of this article.

\section{Ethical approval}

This study was approved by the ethics committee of the Pomeranian Medical University in Szczecin ( ${ }^{0}$ KB-0012/23/15). All patients provided written consent before the inclusion in the study.

\section{REFERENCES}

1. Rabaan AA, Saunar JV, Bazzi AM, et al. Modified use of real-time PCR detection of group B Streptococcus in pregnancy. J Med Microbiol. 2017; 66(10): 1516-1520, doi: 10.1099/jmm.0.000604, indexed in Pubmed: 28920845.

2. Pitts S, Maruthur N, Langley G, et al. Obesity, Diabetes, and the Risk of Invasive Group B Streptococcal Disease in Nonpregnant Adults in the United States. Open Forum Infectious Diseases. 2018; 5(6), doi: 10.1093/ofid/ofy030.

3. Romero R, Dey SK, Fisher SJ. Preterm labor: one syndrome, many causes. Science. 2014; 345(6198): 760-765, doi: 10.1126/science.1251816, indexed in Pubmed: 25124429.

4. Matoso A, Shapiro S, De Paepe ME, et al. Placental intravascular organisms: a case report. J Perinatol. 2010; 30(10): 688-690, doi: 10.1038/jp.2010.63, indexed in Pubmed: 20877362.

5. Nan C, Dangor Z, Cutland CL, et al. Maternal group BStreptococcus-related stillbirth: a systematic review. BJOG: An International Journal of Obstetrics \& Gynaecology. 2015; 122(11): 1437-1445, doi: 10.1111/14710528.13527.

6. McClure EM, Goldenberg RL. Infection and stillbirth. Semin Fetal Neonatal Med. 2009; 14(4): 182-189, doi: 10.1016/j.siny.2009.02.003, indexed in Pubmed: 19285457. 
7. Edmond K, Kortsalioudaki C, Scott S, et al. Group B streptococcal disease in infants aged younger than 3 months: systematic review and meta-analysis. The Lancet. 2012; 379(9815): 547-556, doi: 10.1016/s01406736(11)61651-6.

8. Dagnew AF, Cunnington $M C$, Dube $Q$, et al.Variation in reported neonatal group B streptococcal disease incidence in developing countries. Clin Infect Dis. 2012; 55(1): 91-102, doi: 10.1093/cid/cis395, indexed in Pubmed: 22523262

9. Rivera L, Sáez-Llorens X, Feris-Iglesias J, et al. Incidence and serotype distribution of invasive group $B$ streptococcal disease in young infants: a multi-country observational study. BMC Pediatr. 2015; 15: 143, doi: 10.1186/s12887-015-0460-2, indexed in Pubmed: 26427955.

10. Melin P. Neonatal group B streptococcal disease: from pathogenesis to preventive strategies. Clin Microbiol Infect. 2011; 17(9): 1294-1303, doi: 10.1111/j.1469-0691.2011.03576.x, indexed in Pubmed: 21672083.

11. Centers for Disease Control and Prevention. Prevention of group B streptococcal disease. MMWR. 2010; 59: 1-32.

12. Verani JR, Mcgee L, Schrag SJ. Division of bacterial diseases, national center for immunization and respiratory diseases, centers for disease control, and prevention. Prevention of perinatal group B streptococcal disease-revised guidelines from CDC. MMWR. 2010; 59: 1-36.

13. El Helali N, Nguyen JC, Ly A, et al. Diagnostic accuracy of a rapid real-time polymerase chain reaction assay for universal intrapartum group $B$ streptococcus screening. Clin Infect Dis. 2009; 49(3): 417-423, doi: 10.1086/600303, indexed in Pubmed: 19580414.

14. Mueller M, Henle A, Droz S, et al. Intrapartum detection of Group B streptococci colonization by rapid PCR-test on labor ward. Eur J Obstet Gynecol Reprod Biol.2014; 176: 137-141, doi: 10.1016/j.ejogrb.2014.02.039, indexed in Pubmed: 24680393.

15. de Tejada BM, Pfister RE, Renzi G, et al. Intrapartum Group B streptococcus detection by rapid polymerase chain reaction assay for the prevention of neonatal sepsis. Clin Microbiol Infect. 2011; 17(12): 1786-1791, doi: 10.1111/j.1469-0691.2010.03378.x, indexed in Pubmed: 20860701.

16. Edwards JM, Watson N, Focht C, et al. Group B Streptococcus (GBS) Colonization and Disease among Pregnant Women: A Historical Cohort Study. Infect Dis Obstet Gynecol. 2019; 2019: 5430493, doi: 10.1155/2019/5430493, indexed in Pubmed: 30853787.

17. Young B, Dodge L, Gupta $M$, et al. Evaluation of a rapid, real-time intrapartum group $B$ streptococcus assay. American Journal of Obstetrics and Gynecology. 2011; 205(4): 372.e1-372.e6, doi: 10.1016/j.ajog.2011.06.087.
18. Gavino M, Wang E. A comparison of a new rapid real-time polymerase chain reaction system to traditional culture in determining group B streptococcus colonization. Am J Obstet Gynecol. 2007; 197(4): 388.e1-388. e4, doi: 10.1016/j.ajog.2007.06.016, indexed in Pubmed: 17904971.

19. Towers CV, Rumney PJ, Asrat T, et al. The accuracy of late third-trimester antenatal screening for group B streptococcus in predicting colonization at delivery. Am J Perinatol. 2010; 27(10): 785-790, doi: 10.1055/s-00301254237, indexed in Pubmed: 20458663.

20. Davies HD, Miller MA, Faro S, et al. Multicenter study of a rapid molecular-based assay for the diagnosis of group B Streptococcus colonization in pregnant women. Clin Infect Dis. 2004; 39(8): 1129-1135, doi: 10.1086/424518, indexed in Pubmed: 15486835.

21. Plainvert C, El Alaoui F, Tazi A, et al. Intrapartum group B Streptococcus screening in the labor ward by Xpert ${ }^{\oplus} \mathrm{GBS}$ real-time PCR. Eur J Clin Microbiol Infect Dis. 2018; 37(2): 265-270, doi: 10.1007/s10096-017-3125-2, indexed in Pubmed: 29082442.

22. Helmig RB, Gertsen JB. Diagnostic accuracy of polymerase chain reaction for intrapartum detection of group B streptococcus colonization. Acta Obstet Gynecol Scand. 2017; 96(9): 1070-1074, doi: 10.1111/aogs.13169, indexed in Pubmed: 28504863.

23. Said M, Dangor Y, Mbelle N, et al. Comparison of Xpert GBS v. culture for rapid detection of group $B$ streptococcus in pregnant women: Sensitivity, specificity and predictive values. S Afr Med J. 2018; 108(12): 1032-1035, doi: 10.7196/SAMJ.2018.v108i12.13079, indexed in Pubmed: 30606287.

24. Park JSu, Cho DH, Yang JH, et al. Usefulness of a rapid real-time PCR assay in prenatal screening for group B streptococcus colonization. Ann Lab Med. 2013; 33(1): 39-44, doi: 10.3343/alm.2013.33.1.39, indexed in Pubmed: 23301221.

25. Feuerschuette OH, Silveira SK, Cancelier AC, et al. Diagnostic yield of real-time polymerase chain reaction in the diagnosis of intrapartum maternal rectovaginal colonization by group B Streptococcus: a systematic review with meta-analysis. Diagn Microbiol Infect Dis. 2018; 91(2): 99-104, doi: 10.1016/j.diagmicrobio.2018.01.013, indexed in Pubmed: 29454653.

26. Kim E, Oh K, Kim M, et al. Risk Factors for Group B Streptococcus Colonization Among Pregnant Women in Korea. Epidemiology and Health. 2011; 33: e20110010, doi: 10.4178/epih/e2011010.

27. Parente V, Clark RH, Ku L, et al. Risk factors for group B streptococcal disease in neonates of mothers with negative antenatal testing. Journal of Perinatology. 2016; 37(2): 157-161, doi: 10.1038/jp.2016.201. 